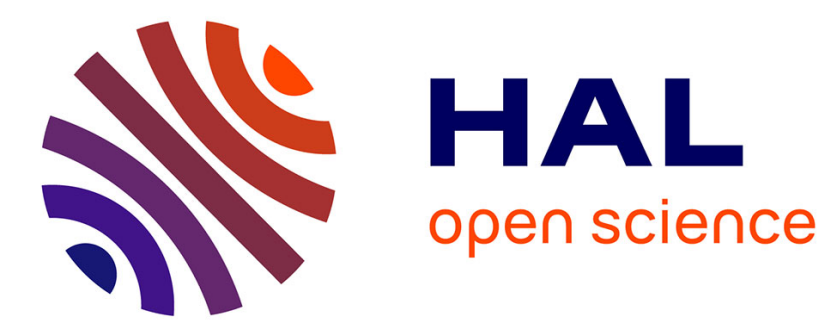

\title{
"La noblesse provinciale à table : les dépenses alimentaires de Marie-Joséphine de Galatheau (Bordeaux,1754-1763)"
}

Philippe Meyzie

\section{- To cite this version:}

Philippe Meyzie. "La noblesse provinciale à table : les dépenses alimentaires de Marie-Joséphine de Galatheau (Bordeaux,1754-1763)". Revue d'Histoire Moderne et Contemporaine, 2007, 54-2, pp.32-54. 10.3917/rhmc.542.0032 . hal-02264294

\section{HAL Id: hal-02264294 \\ https://hal.science/hal-02264294}

Submitted on 7 Aug 2019

HAL is a multi-disciplinary open access archive for the deposit and dissemination of scientific research documents, whether they are published or not. The documents may come from teaching and research institutions in France or abroad, or from public or private research centers.
L'archive ouverte pluridisciplinaire HAL, est destinée au dépôt et à la diffusion de documents scientifiques de niveau recherche, publiés ou non, émanant des établissements d'enseignement et de recherche français ou étrangers, des laboratoires publics ou privés. 


\section{Les goûts alimentaires pluriels des élites provinciales au siècle des Lumières : les dépenses de table de Marie-Joséphine de Galatheau à Bordeaux (1754-1763)}

\section{Philippe MEYZIE}

(Version auteur)

Les goûts alimentaires sont le lieu d'interactions complexes qui entrecroisent les pratiques d'une époque, d'un milieu social, d'une région et d'un individu ${ }^{1}$. S'ils demeurent le fruit de la liberté de choix de chacun, il est aussi clairement admis que les contraintes qui pèsent sur les comportements alimentaires sont nombreuses. Il ne s'agit pas ici, à travers l'étude des habitudes alimentaires d'une représentante de la riche noblesse bordelaise des Lumières, de dégager de quelconques déterminismes, mais bien d'essayer de comprendre, à travers cet exemple, comment les consommations alimentaires correspondent à une identité plurielle révélatrice de la société provinciale du XVIII ${ }^{\mathrm{e}}$ siècle $^{2}$. Les dépenses alimentaires de Marie-Joséphine de Galatheau, connues jour après jour entre 1754 et $1763^{3}$, permettent à la fois de pénétrer au cœur du quotidien des élites nobiliaires bordelaises, en délaissant la mise en scène sociale des repas d'apparat, et de s'affranchir du regard des hommes pour apercevoir la réalité des consommations féminines ${ }^{4}$. Les livres de comptes domestiques font partie des rares sources qui font entendre la voix de femmes ${ }^{5}$. À l'instar de ce document bordelais, ces écrits du for privé, très prisés des érudits du XIX ${ }^{\mathrm{e}}$ siècle, sont aujourd'hui de nouveau au centre de l'historiographie, mais avec des méthodes et des approches différentes ${ }^{6}$. Il ne s'agit plus d'y voir uniquement des documents exceptionnels retraçant la vie d'une personne ou d'une famille, mais bien d'en comprendre la genèse et surtout l'inscription dans leurs contextes. Si les livres de raison sont la source privilégiée de cette démarche, les livres de comptes peuvent également s'inscrire parfaitement dans ce processus ${ }^{7}$. En analysant les

\footnotetext{
1. Jean-Louis FlandRIN, «La diversité des goûts et des pratiques alimentaires en Europe du XVI au XVIII ${ }^{\mathrm{e}}$ siècles », Revue d'histoire moderne et contemporaine, janvier 1983, p. 66-83

${ }^{2}$. Cette approche rejoint la notion de «mangeur pluriel » développée depuis quelques années par les sociologues de l'alimentation comme Jean-Pierre PoulaIN, Penser l'alimentation. Entre imaginaire et rationalité, Toulouse, Privat, 2002, p. 192. «Dire que les mangeurs sont pluriels, cela veut dire tout d'abord qu'ils sont socialement diversifiés - hommes et femmes, jeunes et vieux, plus diplômés et moins diplômés, urbains et ruraux, mariés et solitaires, sans enfants et avec enfants [...] Dire que les mangeurs sont pluriels, cela veut dire aussi que cohabitent une pluralité de logiques et une pluralité d'attitudes chez un même individu au fils du temps. » Pour une réflexion récente sur la notion d'identité et son utilisation par les historiens, voir Identités, appartenances, revendications identitaires (XVI $-X V I I I^{e}$ siècles), Edition préparée par MARC BELISSA, MONIQUE COTTRET, LAURENCE CROQ et JEAN DUMA, Paris, Nolin, 2005.

${ }^{3}$. Archives départementales de la Gironde (désormais AD 33), Fonds Duvergier, 10 J 70.

4. L'autonomie éventuelle des femmes dans ce domaine reste encoure un sujet à explorer; voir François Cadiou, Clarisse Coulomb, Anne Lemonde et Yves Santamaria, Comment se fait l'histoire. Pratiques et enjeux, Paris, La Découverte, 2005, p. 327-333.

5. Amanda VICKERY, « «S'il vous plait, brûlez cela afin qu'aucun œil mortel ne puisse le voir »: les secrets de sources féminines », dans Jean-Pierre BARDET et François-Joseph RUGGIU, Au plus près du secret des cœurs? Nouvelles lectures historiques des écrits du for privé en Europe du XVI au XVIII siècle, Paris, Presses Universitaires Paris-Sorbonne, 2005, p. 43-62.

${ }^{6}$. Jean TRICARD, «Les livres de raison français au miroir des livres de famille italiens : pour relancer une enquête ", Revue historique, oct-déc 2002, p. 993-1011 ; Jean-Pierre BARDET et François-Joseph RUGGIU, $A u$ plus près du secret des cours? Nouvelles lectures historiques des écrits du for privé en Europe du XVI au XVIII ${ }^{e}$ siècle, Paris, Presses Universitaires Paris-Sorbonne, 2005

7. En reprenant la définition de Furetière en 1690 selon laquelle « le livre de raison est un livre dans lequel un bon mesnager ou un marchand escrit tout ce qu'il reçoit et despenses pour se rendre compte et à raison à luy mesme de toutes ses affaires », Valérie Piétri souligne, d'ailleurs à juste titre, que les livres de raison, terme
} 
dépenses du noble languedocien, Henry Jean Antoine de Roquefeuil, marquis de Londres, Josef Smets a ainsi pu reconstituer avec minutie ses pratiques alimentaires, les rythmes saisonniers de ses consommations ou bien encore les variations de son régime alimentaire dues à la maladie ${ }^{8}$. Grâce à la précision des dépenses de table notées par Marie-Joséphine de Galatheau, il s'agit d'essayer de dresser un profil alimentaire, c'est-à-dire de distinguer des goûts, des pratiques alimentaires au quotidien, la répartition des dépenses de bouche, un rapport à la nourriture ou bien encore le respect ou non des règles du Carême. Pour cela, il est nécessaire de s'écarter d'une étude centrée sur les sommes consacrées à chaque aliment -qui reste fortement conditionnée par la valeur des produits- pour s'intéresser, en priorité, aux fréquences d'achats des produits, plus révélatrices, nous semble-t-il, des goûts alimentaires. À travers cette grille d'analyse globale, comparée aux habitudes alimentaires du Sud-Ouest aquitain dans son ensemble ${ }^{9}$, il est alors possible d'éclairer les fondements des goûts et de comprendre, à travers les consommations de cette riche Bordelaise, comment chacun s'insère dans des espaces sociaux, géographiques et culturels multiples. L'étude de ce profil alimentaire à partir de l'ensemble des habitudes de consommation d'un individu invite à s'interroger sur la pertinence de la séparation trop schématique entre culture populaire et culture élitaire -déjà observée dans d'autres champs de la discipline historique ${ }^{10}$ - mais aussi modernité et tradition, exotisme et enracinement ${ }^{11}$. Les goûts alimentaires de Mlle de Galatheau révèlent-ils avant tout de son identité féminine, de son appartenance à la noblesse des Lumières, de son immersion dans une culture alimentaire bordelaise originale partagée par tous, au-delà des barrières sociales, ou bien peut-être des trois à la fois ?

\section{Des goûts féminins ?}

La spécificité des consommations féminines en matière d'alimentation reste très difficile à discerner pour l'historien. Rares sont en effet les documents qui permettent d'isoler les aliments ou les manières de faire propres aux femmes. Par ses conditions d'élaboration et par le profil de sa rédactrice, le livre de dépenses de table de Mlle de Galatheau, permet, dans une certaine mesure, d'y remédier et d'envisager, à travers ses habitudes alimentaires, les contours de ce qui pourrait être une identité féminine en ce domaine.

\footnotetext{
générique aux réalités multiples, peuvent également être des livres de comptes. Valérie PIÉTRI, «Le livre de raison en Provence aux XVII ${ }^{\mathrm{e}}$ et XVIII ${ }^{\mathrm{e}}$ siècles : entre livre de compte et livre de famille », Provence historique, juillet-septembre 2004, p. 315-328. Cette position est également soutenue par Jean TRICARD, «Les livres de raison français au miroir des livres de famille italiens... », art. cit., p. 999, pour qui les livres de raison sont avant tout « une mémoire comptable et familiale appliquée aux biens et aux hommes. »

${ }^{8}$. Josef SMETS, «A la table d'un seigneur languedocien en $1766:$ les comptes du cuisinier », RHMC, octobredécembre 2001, p. 32-49. Le livre de comptes de Louis de Maussabré a également permis de reconstituer les consommations plutôt modestes d'un gentilhomme de Touraine, Brigitte MAILLARD, «En Touraine au XVIII ${ }^{\mathrm{e}}$ siècle. Vie et mort d'un gentilhomme campagnard », dans B. MAILlARD, Vivre en Touraine au XVIII ${ }^{e}$ siècle, Rennes, Presses Univ. de Rennes, 2003, p. 113-120.

9 . Cette démarche se fonde en particulier sur les résultats obtenus dans le cadre de notre thèse ; Philippe MEYZIE, Culture alimentaire et société dans le Sud-Ouest aquitain du XVIII au milieu du XIX ${ }^{e}$ siècle : goûts, manières de table et gastronomie. L'émergence d'une identité régionale, thèse de doctorat de l'Université Michel de Montaigne-Bordeaux III, dir. Josette PONTET, 2005, 3 tomes, 905 p.

10. Les possibles échanges entre culture des élites et culture populaire dans le domaine de l'alimentation pourraient en effet se rapprocher de ce qui a déjà été observé à propos du livre ; voir Roger CHARTIER, Au bord de la falaise. L'histoire entre certitudes et inquiétude, Paris, Albin Michel, 1998.

${ }^{11}$. L'histoire des consommations, par le biais des processus complexes d'acculturation interroge particulièrement la pertinence de ces définitions et de cette scission; voir Dominique PoUlot, «Culture matérielle et consommation. Remarques sur une historiographie », dans René FAVIER, (dir.), Terres et hommes du Sud-Est sous l'Ancien Régime. Mélanges offerts à Bernard Bonnin, Grenoble, Presses Univ. de Grenoble, 1996, p. 231248.
} 
Marie-Joséphine de Galatheau appartient à une noblesse bordelaise partagée entre le Parlement et la Jurade ${ }^{12}$ : son père, François-Joseph de Galatheau, écuyer et jurat, épouse en 1721 Joséphine-Louis Lecomte de Latresne, fille d'un conseiller au parlement. Au XVIII ${ }^{\mathrm{e}}$ siècle, sa famille compte d'autres membres de la Jurade comme son frère aîné François-Léon. Marie-Joséphine est née le 2 novembre 1727 en la paroisse Saint-André ; célibataire, elle a donc entre 27 et 36 ans lorsqu'elle tient ses comptes de 1754 à $1763^{13}$. Elle vit dans une demeure située 42 rue Porte-Dijeaux ${ }^{14}$, dans un quartier où se côtoient élites parlementaires et négociantes. Une contribution acquittée en 1814 confirme qu'à 87 ans elle vit toujours seule dans cette maison ${ }^{15}$. Parfois, les comptes font mention d'une ou deux nièces séjournant chez elle ; Mlle de Galatheau s'est en effet chargée d'élever sa nièce Thérèse -qui a perdu sa mèrede 1756 jusqu'à son mariage en 1771 avec Monsieur de Montaigne ${ }^{16}$. S'il est impossible de connaître avec certitude le niveau de sa fortune, la nature des dépenses alimentaires et surtout le contenu de son testament laisse juste supposer que cette dame vit dans l'aisance. Dans ce testament non daté, conservé à l'intérieur de son livre de dépenses de table, elle n'hésite pas à faire don de 1000 livres-tournois à sa femme de chambre, Suzanne Brocate, et à constituer une belle rente de 38000 lt. pour sa nièce, Mme de Montaigne, autant indices d'une richesse importante ${ }^{17}$.

Marie-Joséphine vit entre son hôtel bordelais et le château de Lestonnac, demeure familiale située à Gradignan, à proximité de Bordeaux. Ce système de double résidence très répandu dans les élites bordelaises du siècle des Lumières et qui se retrouve dans bien d'autres villes confirme la fortune du personnage ${ }^{18}$. Vivre entre ville et campagne n'est pas sans influence sur son comportement alimentaire. L'autoconsommation joue, semble-t-il, un rôle ponctuel mais essentiel, comme souvent chez les élites ${ }^{19}$, lorsqu'elle vit à Gradignan. Cela semble être le cas en 1759 et 1760 et justifie, par conséquent, la réduction significative du nombre d'achats alors limités au pain, aux différentes graisses et à la viande ${ }^{20}$. Son séjour lui permet également de veiller aux soins des vendanges, comme en témoignent divers frais de nourriture pour les vendangeurs (notamment des quantités très importantes de $\operatorname{sardines}^{21}$ ). Cependant l'essentiel des dépenses notées dans le livre de comptes concerne les périodes où

\footnotetext{
12. Sur la Jurade et les magistrats municipaux bordelais, voir Laurent CoSTE, Messieurs de Bordeaux. Pouvoirs et hommes de pouvoirs à l'hôtel de ville (1548-1789), Bordeaux, FHSO, 2006. Sur les élites bordelaises du XVIII ${ }^{\mathrm{C}}$ siècle en général, voir Michel FIGEAC, «Les élites bordelaises », dans M. FIGEAC, (dir.), Histoire des Bordelais. La modernité triomphante (1715-1815), Bordeaux, Mollat-FHSO, 2002, p. 55-83.

13. En ville, près d'une femme sur deux vit seule selon Scarlett BEAUVALET-BoutouYRIE, Les femmes à l'époque moderne (XVI ${ }^{e}$-XVIII ${ }^{e}$ siècles), Paris, Belin, 2003, p. 77. La vie des femmes en solitaire est une pratique qui progresse au XVIII ${ }^{\mathrm{e}}$ siècle, Arlette FARGE, Madame ou Mademoiselle. Itinéraires de la solitude féminine, Paris, 1984.

${ }^{14}$. Elle possède également deux chais situés rue des Carmélites.

15. Archives municipales de Bordeaux (ci-après AM Bx), Fonds Beaumartin, dossier XLII. Parmi les documents conservés dans ce dossier consacré à Mlle de Galatheau se trouvent également des factures des années 1810 et 1811. On peut supposer qu'elle décède aux alentours de 1815.

16. Thérèse est la fille de François-Léon de Galatheau et de Marie-Anne Daly morte en 1756.

17. La présence de domestiques (au moins un cuisinier et une servante) pose la délicate question de savoir qui consomme les aliments achetés par Mlle de Galatheau. Les informations fournies par le livre de dépenses de table ne permettent pas d'y répondre, même si on peut supposer que les quantités mentionnées ne peuvent concerner uniquement la maîtresse de maison. Des mentions ponctuelles d'achats comme les « harengs pour les gens » le 5 avril 1762, semblent cependant indiquer que les aliments uniquement réservés aux domestiques sont clairement distingués de ceux destinés à l'ensemble de la maisonnée.

18. M. FIGEAC, La douceur des Lumières. Noblesse et art de vivre en Guyenne au XVIII siècle, Bordeaux, Mollat, 2001 ; Jean MEYER, La noblesse bretonne au XVIII siècle, Paris, EPHE, 1966, p. 1180.

${ }^{19}$. Florent QUELLIER, «Le jardin fruitier-potager, lieu d'élection de la sécurité alimentaire à l'époque moderne », RHMC, t. 51, n ${ }^{\circ} 3$, juillet-septembre 2004, p. 66-78.

${ }^{20}$. Ces achats de viande et de pain sont effectués chez un boucher de Léognan et un boulanger de Gradignan.

${ }^{21}$. 600 sardines sont ainsi notées parmi les dépenses du septembre 1762 .
} 
elle séjourne à Bordeaux au cours desquelles les achats sont particulièrement nombreux et variés $^{22}$. La part de l'autoconsommation y est alors très réduite, puisque des produits, habituellement absents de ce genre de source, tels les légumes ou les fruits sont régulièrement mentionnés. Ce dernier élément renforce l'intérêt exceptionnel de ce document en réduisant les distorsions entre achats et consommation ${ }^{23}$. Pourquoi cette riche Bordelaise choisit-elle de noter presque au jour le jour ses dépenses de bouche durant une aussi longue période ?

Tous ses achats alimentaires sont soigneusement consignés dans un grand registre relié en cuir d'environ $34 \mathrm{~cm}$ sur $22 \mathrm{~cm}$ et fermé par des lanières, comprenant au total 198 feuillets et seulement 12 pages blanches à la fin. La plupart des pages sont divisées en colonnes : une pour la date, une autre pour la nature des aliments et une dernière pour les sommes dépensées.

\footnotetext{
${ }^{22}$. On s'écarte donc là des schémas de l'alimentation seigneuriale des gentilshommes ruraux qui profitent de moyens variés d'approvisionnement tels le métayage ou les droits seigneuriaux.

23. Sur le délicat problème de l'autoconsommation, voir Maurice AYMARD, «Autoconsommation et marchés : Chayanov, Labrousse ou Le Roy Ladurie », Annales ESC, 1983, p. 1392-1410.
} 
Page du livre de dépenses de Marie-Joséphine de Galatheau (année 1762)

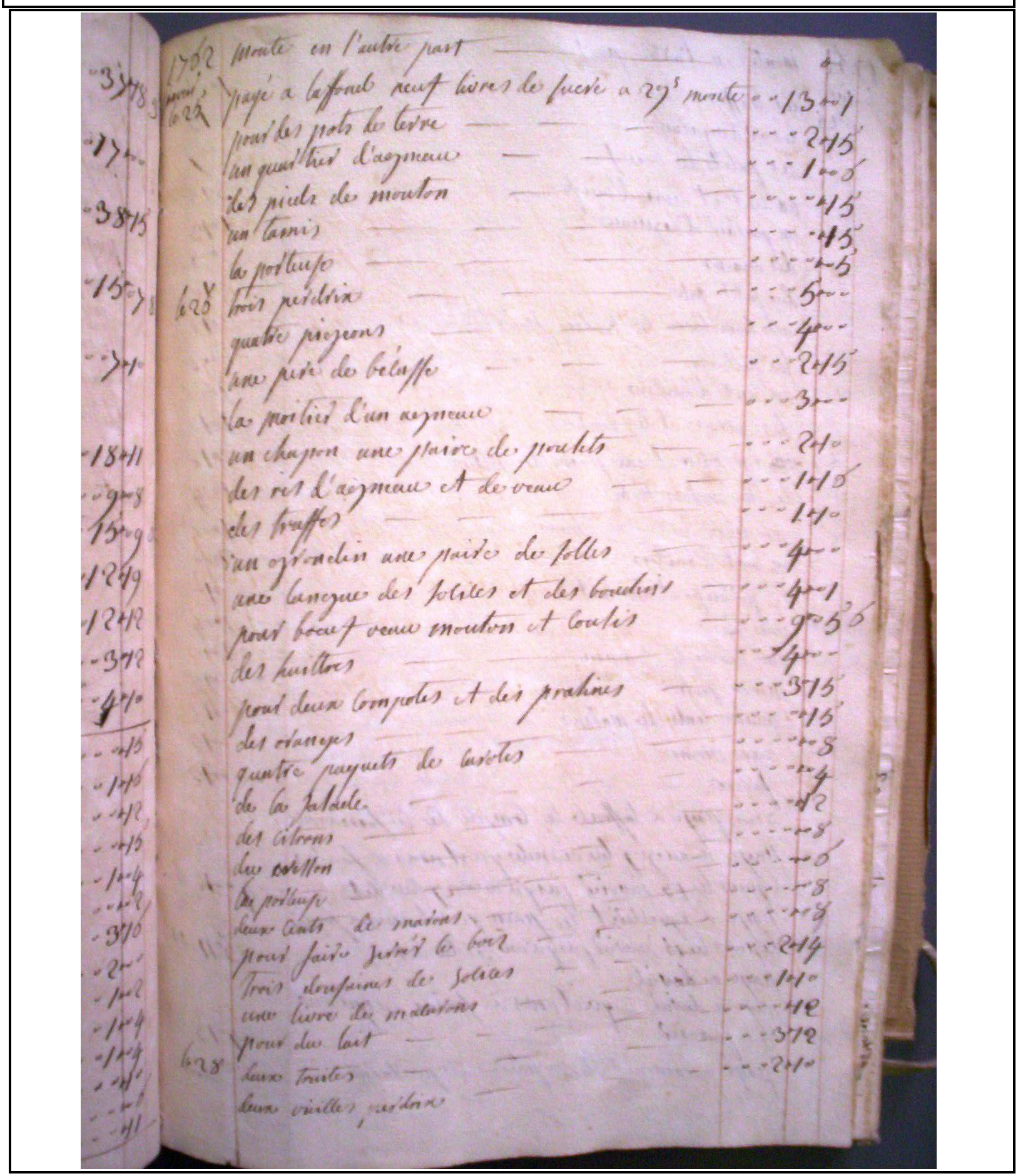

Source : AD Gironde $10 \mathrm{~J} 70$

À l'intérieur, on observe un découpage par année et par mois avec, en moyenne, un relevé des dépenses alimentaires tous les deux ou trois jours. L'originalité de ce document réside en premier lieu dans son extrême précision, puisque, outre le prix et la nature des aliments 
achetés, il est fréquent de trouver mention de modes de préparation culinaires comme, par exemple, l'achat de «veau pour le coulis » ou « un morceau de veau pour la broche ». Des achats concomitants et répétés de certains produits peuvent laisser supposer des associations alimentaires habituelles sur la table de Mlle de Galatheau.

Rédigés sans doute de la main même de Marie-Joséphine, ces comptes qui s'étendent très exactement du $1^{\text {er }}$ janvier 1754 au 21 décembre 1763, révèlent une écriture souple et bien lisible, signe d'une attention toute particulière accordée aux tâches de gestionnaire, plutôt courante dans la noblesse ${ }^{24}$. La tenue d'un livre de dépenses domestiques relève, peut-être, d'une tradition familiale qui expliquerait la prise de plume de la jeune Marie-Joséphine, puisque son frère François-Léon, prend également soin de noter régulièrement ses achats quotidiens dans les années suivantes ${ }^{25}$. La durée couverte par les comptes de Mlle de Galatheau et leur régularité tout à fait exceptionnelle permettent de s'affranchir du poids des dépenses festives qui faussent souvent des relevés effectués sur des périodes brèves en liaison avec des événements particuliers comme un repas de mariage ou un banquet édilitaire. Pour comprendre vraiment les goûts des élites sociales, il ne faut pas se limiter à l'alimentation d'exception, mais s'intéresser aussi aux consommations quotidiennes. Grâce à ce document, il est enfin possible d'accéder au premier niveau de l'alimentation défini par Daniel Roche : la cuisine familiale, quotidienne et privée ${ }^{26}$. Au total, 11105 achats alimentaires ont été effectués sur ces dix années, mais avec des variations notables ${ }^{27}$. L'année 1762 est nettement plus détaillée que les autres ; les achats sont notés jour après jour ce qui constitue une exception car les relevés peuvent concerner des semaines entières. Certaines années, les dépenses sont rassemblées par groupes, ce qui rend impossible l'analyse détaillée et complète des sommes consacrées à chacun des aliments ${ }^{28}$. Enfin, il est intéressant de souligner jusqu'au titre qui figure sur la couverture, «Dépence de la table » : la dernière originalité de ce document vient qu'il est consacré, quasi exclusivement, aux dépenses alimentaires ${ }^{29}$, alors que, couramment, celles-ci sont mêlées aux comptes de métairies, aux crédits ou aux achats vestimentaires. Ceci révèle, peut-être, un attrait particulier de Mlle de Galatheau pour la nourriture et les soins de la cuisine. À l'intérieur du registre plusieurs factures sur papiers libres concernent des achats effectués chez le traiteur, des frais d'étameurs ou des comptes d'huile, rangées sans doute ici pour les insérer dans l'ensemble des comptes et justifier certaines dépenses. L'existence même de ce livre de dépenses de table témoigne de la responsabilité des femmes dans la gestion de la sphère privée et domestique ${ }^{30}$. Si elle existe pour les femmes mariées, signe d'une certaine autonomie ménagère, c'est encore plus vrai, dans les élites sociales, pour les femmes seules, célibataires ou veuves, à qui incombent l'intégralité des soins de la maison.

\footnotetext{
24. Dominique Godineau, Les femmes dans la société française. 16 $16^{e} 18^{e}$ siècle, Paris, Armand Colin, 2003, p. 35.

25. AM Bx, Fonds Beaumartin, dossier XLII, 1765-1790 et AD 33, 17 J 81-82.

${ }^{26}$. Le deuxième étant la cuisine collective et utilitaire, et le dernier la cuisine de fête et d'apparat. Daniel RochE, «Le vin, le pain, le goût», dans Jean-Luc MAYAUD, Clio dans les vignes. Mélanges offerts à Gilbert Garrier, Lyon, 1998, p. 273.

27. Année 1754 (1493 achats alimentaires), 1755 (1549), 1756 (1354), 1757 (1114), 1758 (1432), 1759 (203), 1760 (388), 1761 (1570), 1762 (1694), 1763 (308).

28. Par conséquent, nous avons choisi d'étudier en priorité les fréquences d'achat des aliments, tout aussi révélatrices, selon nous, des goûts. Nous avons effectué une analyse des dépenses pour l'année 1762, la plus détaillée, qui corrobore les résultats obtenus à partir des fréquences. Pour les années 1759, 1760 et 1763 , les relevés des dépenses, beaucoup trop lacunaires, rendent de toute manière impossible l'analyse d'ensemble des sommes consacrés à chaque aliment.

${ }^{29}$. Figurent régulièrement, parmi les achats alimentaires, les dépenses consacrées aux chandelles et à l'envoi de lettres, ainsi qu'au charbon et au bois utilisés, vraisemblablement, pour cuisiner.

30. Jean-Marie BARBIER, Le quotidien et son économie. Essai sur les origines historiques et sociales de l'économie familiale, Paris, CNRS, 1981, p. 35.
} 
L'emploi d'un cuisinier, dénommé Laffond ${ }^{31}$ et mentionné au milieu des dépenses de l'année 1762, suggère que la tenue de ce registre servait aussi à surveiller les provisions confiées au cuisinier. Pour Marie-Joséphine de Galatheau, noter, avec soin et au quotidien, les dépenses alimentaires lui permet à la fois de contrôler les sommes consacrées à la nourriture, de prévoir les futurs dépenses -ce qui correspond aux devoirs d'une bonne maîtresse de maison- et de satisfaire à ses envies gourmandes.

L'existence de ce livre de dépenses de table invite aussi à s'interroger sur le rapport que cette dernière entretient avec la nourriture. Ne pourrait-on pas déceler éventuellement dans ce domaine une spécificité féminine ? Cette riche Bordelaise apparaît en premier lieu comme une femme pieuse ou, tout du moins, respectueuse des interdits alimentaires de l'Église. On constate en effet des rythmes annuels dans ses dépenses correspondant au Carême. À partir de l'exemple de l'année 1755, l'une des plus détaillées, les sommes consacrées à la viande, en très net recul entre février et avril, sont supplantées par une hausse significative des achats de poisson. Le temps du Carême, situé du 16 février au 30 mars en 1755, est précisément le seul moment de l'année où les achats de poisson sont plus nombreux en quantité que ceux de viande ${ }^{32}$.

\section{GraphiQue}

La consonmation de viande et de poisson de Mlle de Galatheau en 1755

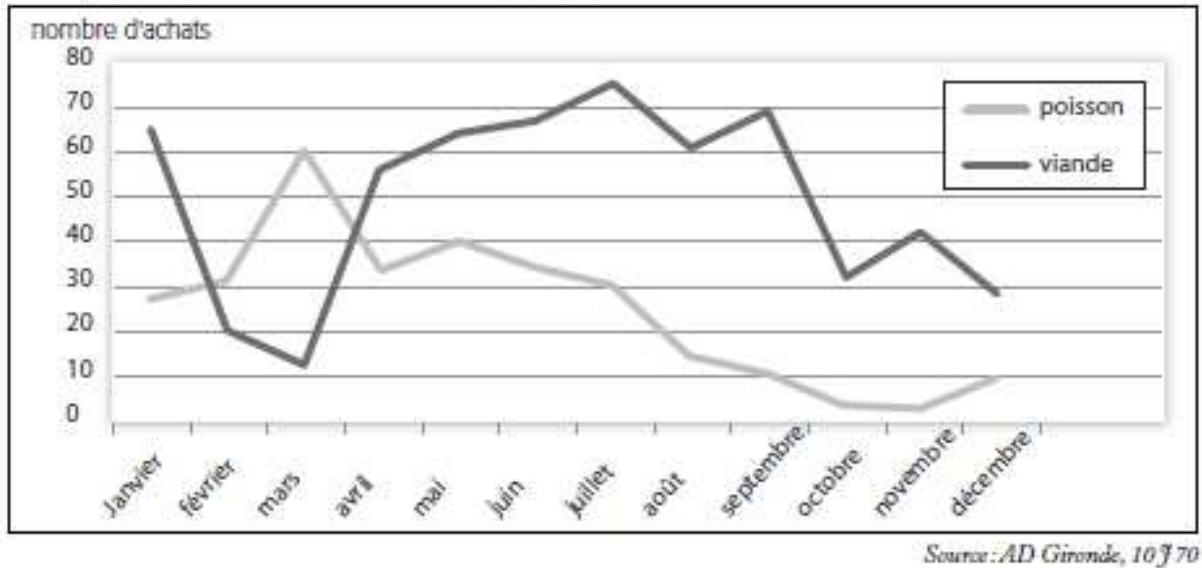

Dans les rythmes alimentaires hebdomadaires, le même respect des règles du maigre transparait. Chaque semaine, en effet, Mlle de Galatheau achète du poisson pour les repas du vendredi et du samedi. Il est toutefois impossible de distinguer avec certitude les consommations du jour même car les achats peuvent être effectués la veille ou l'avant-veille. Le livre de dépenses permet en revanche de préciser la consommation alimentaire des jours maigres : du poisson frais et de la morue séchée auxquels s'ajoutent quelquefois des œufs. Plus surprenant est la présence de beurre frais à cette occasion. Le Sud-Ouest aquitain bénéficie d'une tolérance vis-à-vis du beurre ces jours-là et les élites ne s'en privent pas, notamment pour accompagner la morue qui nécessite beaucoup de matière grasse pour être cuisinée lorsqu'elle a été séchée. Le cas de cette riche Bordelaise laisse penser qu'en ce

\footnotetext{
${ }^{31}$. Ce cuisinier apparaît également au détour des comptes de François-Léon de Galatheau à la fin des années 1760 ce qui laisse supposer soit que Laffond passe du service de Mlle de Galatheau à celui de son frère, soit, plus vraisemblablement, que les deux vivent ensemble et que les livres de comptes se succèdent simplement. Aucun indice ne permet cependant de trancher cette question avec certitude.

32. Tous les ans le même phénomène se répète entre 1754 et 1762.
} 
milieu du XVIII ${ }^{\mathrm{e}}$ siècle, contrairement à ce qui a pu être observé à Paris ${ }^{33}$, le respect du maigre n'est aucunement en recul, ce qui confirme, par le biais des consommations alimentaires, l'attachement des élites locales à la religion catholique ${ }^{34}$. Marie-Joséphine de Galatheau témoigne aussi de sa dévotion par des cadeaux réguliers faits aux religieuses d'un couvent bordelais. Ils apparaissent parmi les dépenses de table, car il s'agit de présents alimentaires comme du beurre, de la morue ou des soles. Le 16 mars 1755, elle offre ainsi une paire de soles, une perdrix, de la morue blanche-c'est-à-dire fraîche-et de la morue sèche aux religieuses. Le 10 mai 1755, elle " paye pour le dîner de messieurs les curés » bœuf, poulets, chapons, levrauts, perdrix, saucisses et boudins, aliments d'un repas sans austérité! Manifestation d'une forme de charité chrétienne contribuant à la promotion de la femme dans la société, ces cadeaux sont également l'illustration de la place des étrennes dans la culture des élites ${ }^{35}$. En respectant les prescriptions alimentaires de l'Église et les coutumes qui les accompagnent ${ }^{36}$, Mlle de Galatheau se conforme à la fois aux devoirs d'une maitresse de maison et aux habitudes de son milieu. L'influence du calendrier chrétien sur ses habitudes alimentaires ne se limite pas à des interdits, mais prend parfois des formes plus attractives. Les fêtes religieuses sont l'occasion pour elle de s'écarter des nourritures quotidiennes. Le 24 décembre 1757, par exemple, elle achète plus d'aliments qu'à l'ordinaire, un chapon en particulier dont on peut penser qu'il viendra agrémenter son repas de Noël. Les dépenses de bouche se multiplient chaque année à l'approche de Noël, mais également au temps du Carnaval, juste avant le Carême. Durant ces périodes «gourmandes » apparaissent souvent gibiers, truffes, huîtres et autres dindes. Ces agapes exceptionnelles révèlent que Mlle de Galatheau sait faire preuve à l'occasion de gourmandise.

Cet attrait des plaisirs de la chère défini dans l'Encyclopédie comme «un amour raffiné et désordonné de la bonne chère », prend avec Mlle de Galatheau une orientation souvent "féminine ». S'il est très difficile de dégager ses attitudes par rapport à la nourriture, les «friandises ${ }^{37}$ et douceurs nombreuses parmi les comptes témoignent d'une faiblesse certaine pour les pâtisseries sucrées et autres sucreries, plaisir attribué souvent aux femmes ${ }^{38}$. Échaudés, gaufres, cassemuseaux et bonbons variés figurent couramment parmi ses dépenses. Le sucre lui-même occupe une place non négligeable, qu'il s'agisse de sucre blanc raffiné ou de cassonade. Sans doute entre-t-il dans la préparation de gâteaux et autres pâtisseries, mais il sert aussi à accompagner les boissons exotiques comme le café ou le thé ${ }^{39}$. La consommation

\footnotetext{
33. Reynald $\mathrm{ABAD}$, «Un indice de déchristianisation? L'évolution de la consommation de viande à Paris en carême sous l'Ancien Régime », Revue historique, 1999, p. 237.

34. Philippe LOUPÈs, L'apogée du catholicisme bordelais 1600-1789, Bordeaux, Mollat, 2001.

35. Au XVIII ${ }^{\mathrm{e}}$ siècle, la bienfaisance est « un secteur féminin de prédilection» selon S. Beauvalet-Boutouyrie, op. cit. , p. 241. Sur le rôle essentiel des cadeaux alimentaires dans la culture locale, voir P. MEYZIE, «Les cadeaux alimentaires dans la Guyenne du XVIII ${ }^{\mathrm{e}}$ siècle : sociabilité, pouvoirs et gastronomie », revue Histoire, Economie, Société, n ${ }^{1}$, janvier-mars 2006, p. 33-50. Sur la pratique du don dans la France d'Ancien Régime, Natalie ZEMON DAVIS, Essai sur le don dans la France du XVIe siècle, Paris, Seuil, 2003.

${ }^{36}$. Nous avons également pu remarquer que Mlle de Galatheau achète à plusieurs reprises des hosties.

${ }^{37}$. Selon le Dictionnaire universel de Furetière de 1690, « friandise se dit aussi de toutes les choses qu'on mange pour le plaisir seulement, et non pour se nourrir. ». Sur cette notion, voir Mary et Philip HYMAN, « Friandises », dans La Gourmandise. Délices d'un péché, Paris, Autrement, 1993, p. 61-65.

${ }^{38}$. Le célèbre gastronome Brillat-Savarin écrit ainsi, au début du XIX siècle, qu' « il n'est pas de femme, surtout dans l'aisance, qui ne dépense plus d'argent pour son sucre que pour son pain. », Anthelme BRILLAT-SAVARIN, Physiologie du goût, Paris, Flammarion, 1982, p. 111.

39. L'essor de la consommation de sucre est indissociable de celui des boissons exotiques, Alain HUETZ DE LEMPS, «Boissons coloniales et essor du sucre », dans Jean-Louis FLANDRIN et Massimo MonTANARI, Histoire de l'alimentation, Paris, Fayard, 1996, p. 629-641.
} 
journalière de fraises, d'avril à juillet, plutôt rares dans les autres livres de comptes ${ }^{40}$, révèle peut-être un goût particulier de la dame. La comparaison entre les habitudes de MarieJoséphine et celles de son frère montre que ce dernier semble beaucoup moins attiré par ce genre de fruits qui arrive en seconde position parmi les fruits qu'elle achète ${ }^{41}$. Enfin, cerises ou abricots confits confirment tout l'attrait de Mlle de Galatheau pour les saveurs douces. Ce goût du sucré si souvent associé aux femmes paraît le trait le plus significatif du caractère féminin de son alimentation. Cette identité féminine reste par ailleurs fort difficile à déceler dans les dépenses de table de cette riche Bordelaise du siècle des Lumières révélatrices avant tout de la responsabilité d'une maîtresse de maison, des habitudes alimentaires d'une famille et plus largement encore d'un milieu social.

\section{Des goûts à la mode}

Les pratiques alimentaires de Marie-Joséphine de Galatheau s'inscrivent avec une netteté particulière dans les habitudes de consommations des élites des Lumières observables à Paris, mais aussi dans les grandes capitales provinciales. Les goûts de cette riche Bordelaise sont conformes à son rang et guidés par un souci de distinction sociale, une attitude qui se retrouve dans bien d'autres provinces ${ }^{42}$. Ces comptes qui permettent de cerner à la fois le quotidien et l'exceptionnel alimentaires dessinent également l'image d'un mangeur pluriel où se mêlent aux goûts les plus raffinés des habitudes plus rustiques, guères éloignées parfois des consommations du reste de la population.

Cette alchimie complexe se décèle en premier lieu à travers une très grande diversité alimentaire, parfaite illustration des ressources disponibles dans la capitale girondine. La répartition des dépenses par catégorie d'aliment montre que Mlle de Galatheau consomme de la viande, du poisson, mais aussi des légumes et des fruits ${ }^{43}$. Cette variété se maintient tout au long de ces dix années, avec toutefois une légère progression de la part des légumes ${ }^{44}$. Cette diversité est bien supérieure à celle qui se dégage des habitudes de $\mathrm{Mr}$ de Roquefeuil en Languedoc ${ }^{45}$. Aucun aliment ne semble être exclu, a priori, du régime journalier de cette riche Bordelaise. Comme souvent chez les élites, la viande demeure l'achat le plus fréquent (près d'un achat sur trois), mais poissons, légumes et fruits sont aussi fort bien représentés. Chaque jour, Mlle de Galatheau achète ainsi cinq ou six aliments différents en sus du pain qu'elle paye au boulanger en globalité, une fois par semaine. Les achats les plus réguliers témoignent d'un régime alimentaire varié. Morue, veau, beurre, œufs et mouton sont les produits les plus couramment cités ce qui correspond autant à des préférences culinaires qu'aux contraintes

\footnotetext{
${ }^{40}$. Dans la soixantaine de livres de comptes aquitains que nous avons pu étudier, les fraises n'apparaissent qu'à 17 reprises et ce de manière très ponctuelle. Elles sont seulement le $5^{\text {ème }}$ fruit mentionné. P. MEYZIE, Culture alimentaire et société..., op. cit. , p. 775.

${ }^{41}$. AD $33: 17$ J 81-82.

42. J-L. FLANDRIN, «La distinction par le goût », dans Philippe ARIÈS et Georges DUBY, (sous dir. de), Histoire de la vie privée de la Renaissance aux Lumières, Paris, 1986, p. 267-309. Ces consommations distinctives de la noblesse se retrouvent notamment dans les livres de raison provençaux étudiées par V. PIETRI, « «Sage mesnage » ou dissipation : consommation nobiliaire et crédit d'après les livres de raison dracénois au XVIII ${ }^{\mathrm{e}}$ siècle », Provence historique, janvier-mars 2002, p. 87-104.

43. Comme cela a été indiqué précédemment, les consommations de Mlle de Galatheau ont été évaluées non pas à travers les montants des dépenses, mais à travers la fréquence des achats. Cette méthode, malgré ses imperfections, offre l'avantage de gommer l'effet déformant de la valeur des aliments. Par exemple la viande, généralement le produit le plus cher, représente souvent la part la plus importante des dépenses par catégories. Grâce à l'analyse des fréquences, les légumes, pourtant essentiels dans l'alimentation, mais peu chers et donc peu visibles, retrouvent ainsi leur importance réelle en terme de goûts.

44. Dans l'étude des évolutions possibles à travers ce livre de dépenses, il convient de ne pas tenir compte des années 1759,1760 et 1763 , peu représentatives à cause du nombre relativement réduit d'achats.

45. J. SMETS, art. cit.
} 
matérielles d'approvisionnement. Ces aliments proviennent en effet obligatoirement des circuits commerciaux (épicerie, boucherie). Au total, on dénombre plus de 150 aliments différents achetés chaque année au fil des saisons et peut-être aussi des envies de la maîtresse de maison.

GRAPHIQUE 2

Fréquence des achats alimensaires de Mlle de Galatheau, 1754-1763 par catégories

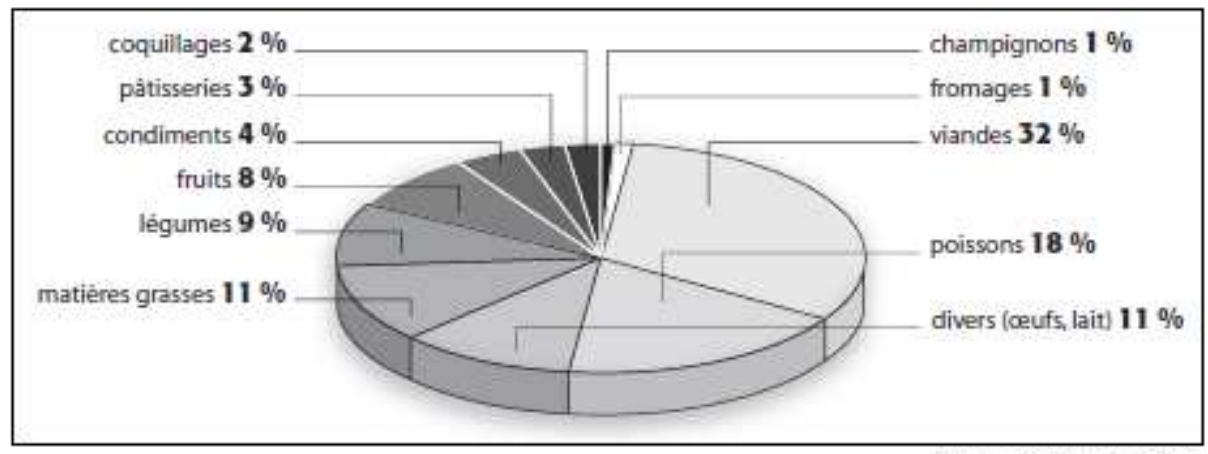

Sourno: $A D$ Gironde, $\log 70$

Graphique 3

les 15 aliments les plus fréquents dans les dépenses de table de Mlle de Galatheau, 1754-1763

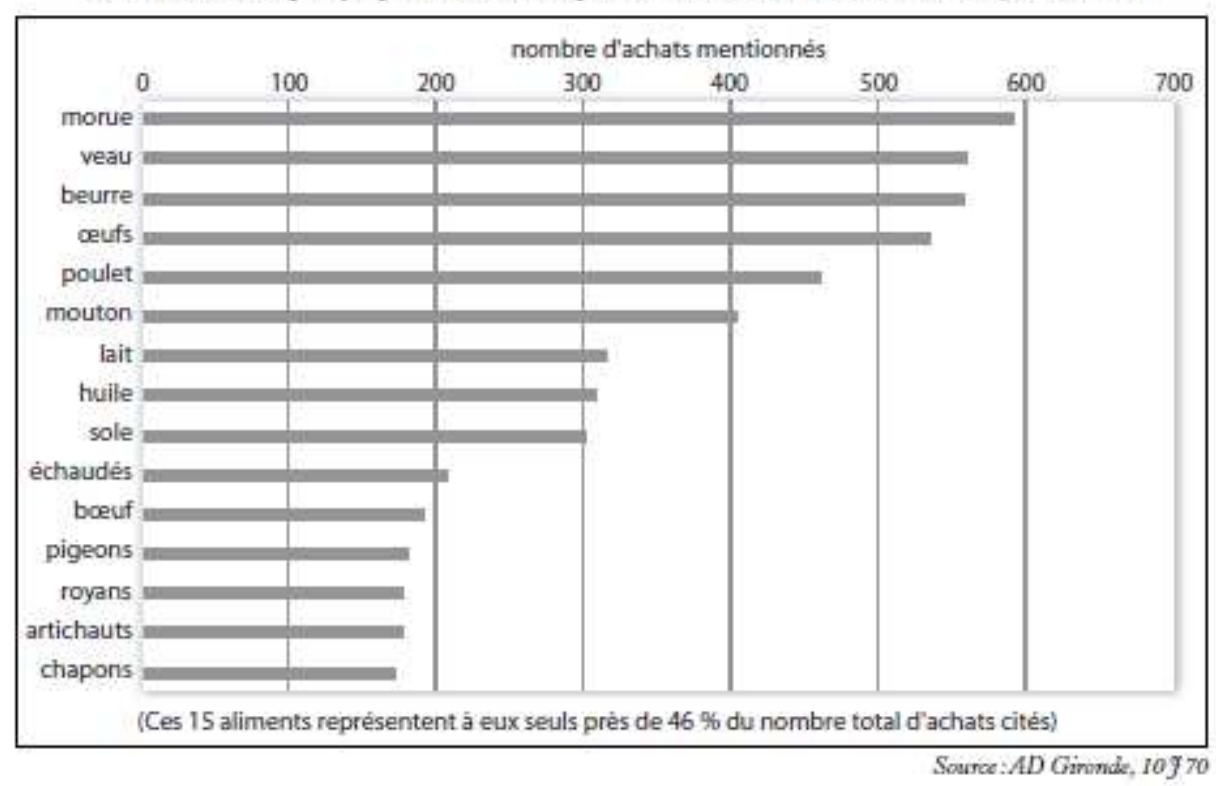

Ces goûts variés correspondent à la mise en œuvre de consommations distinctives, reflet de sa richesse et de son appartenance au second ordre. Les sommes parfois très importantes consacrées à la nourriture rappellent sans équivoque que les revenus de Mlle de Galatheau la situent au sommet de la société bordelaise du XVIII ${ }^{\mathrm{e}}$ siècle. Entre le 22 janvier et le 16 septembre $1762^{46}$, elle dépense en moyenne 7 livres chaque jour, soit près de trois fois le salaire journalier d'un maçon bordelais de cette époque. Cette somme reste tout de même très inférieure aux 22 livres consacrées à son alimentation par $\mathrm{Mr}$ de Roquefeuil en $1766^{47}$. Certaines périodes de l'année voient les dépenses de bouche augmenter de manière significative ; en particulier au mois de janvier où elles atteignent alors 400 à 500 livres par mois. Cette hausse découle du poids des étrennes mais aussi de l'achat de produits onéreux, telles les volailles et les truffes, pour satisfaire aux plaisirs culinaires du Carnaval et de Mardi

\footnotetext{
46. Au total, elle dépense 1634 livres-tournois durant cette période.

${ }^{47}$. Paul BuTEL, L'économie française au XVIII' siècle, Paris, Sedes, 1993, p. 60 et J. SMETS, art. cit., p. 39.
} 
gras avant d'entrer dans les privations du Carême. Incontestablement, les dépenses de bouche de Mlle de Galatheau révèlent une alimentation privilégiée, celle des élites nobiliaires des Lumières.

Les aliments les plus rares, les plus onéreux et les plus recherchés se retrouvent tout naturellement sur la table de Marie-Joséphine. Parmi les viandes, le veau est le plus consommé. Cette viande blanche provenant d'un jeune animal, entourée d'une image de pureté, correspond parfaitement aux goûts des élites. Le veau est cuisiné sous forme de bouilli lorsqu'il s'agit de fricandeau ${ }^{48}$, mais peut également être servi rôti à la broche, mode de cuisson commun chez les élites, comme le suggère la mention, le 31 mai 1761, d'un « morceau de veau pour la broche ». Les dépenses récurrentes pour de la carbonade suggèrent aussi le goût des grillades ${ }^{49}$. La consommation de primeurs et de produits frais, tout au long de l'année, constitue un autre trait distinctif des élites. Dès le mois de mai, cerises et fraises apparaissent dans les comptes, rapidement suivis par les abricots et les pêches. Les multiples achats d'œufs (537 achats soit le quatrième aliment le plus courant) et la présence récurrente de farine (84 mentions) suggèrent la confection de pâtisseries diverses, aussi bien des gâteaux sucrés que des tourtes ou des pâtés, mets ordinairement appréciés par les notables. Il arrive aussi à Mlle de Galatheau d'acheter, sans doute à un pâtissier, des gâteaux sucrés tels des massepains ou des échaudés.

Se conformer à son rang, c'est aussi, pour cette femme de la noblesse bordelaise, suivre au plus près les modes. Or, ses dépenses alimentaires s'inscrivent parfaitement dans les nouvelles orientations de la cuisine telles que les définit La Cuisinière bourgeoise de Menon $^{50}$. La viande de boucherie, longtemps délaissée par les riches ${ }^{51}$, occupe ici une place importante.

\section{GraphiQue 4}

Achats de viande de Mlle de Galatheau entre 1754 et 1763

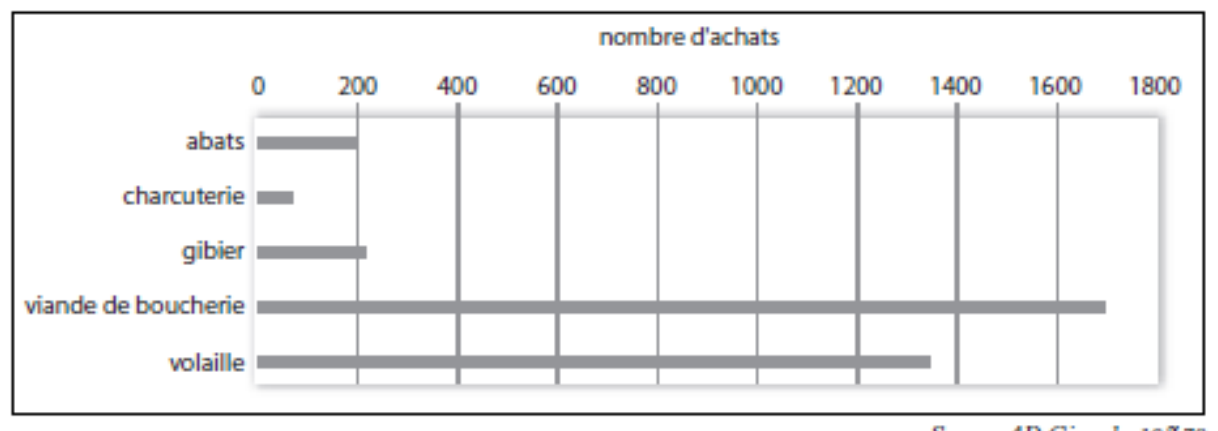

Source: $A D$ Girond, $\log _{70}$

Si cette répartition révèle indiscutablement l'influence des modes parisiennes sur les habitudes alimentaires des élites provinciales, il faut rappeler que la viande de boucherie a toujours eut sa place dans l'alimentation quotidienne des notables. Sur la table de tous les jours, ni gibier ni volaille, mais du porc et du bœuf nourrissent les familles et expliquent que la viande de boucherie représente ici $49 \%$ des achats de viande. La valorisation du bœuf, observée dans les livres de cuisine, est manifeste également dans les achats de Mlle de

\footnotetext{
48. Le terme de fricandeau désigne une tranche de veau très fine servie souvent comme garniture d'entrée.

${ }^{49}$. L'étude de nombreux livres de comptes et menus révèle que le terme de carbonade correspond à une tranche de viande en grillade et, dans la plupart des cas, de veau.

${ }^{50}$. MENON, La Cuisinière bourgeoise, Paris, 1748. Sur cette œuvre de Menon et les livres de cuisine du XVIII ${ }^{\mathrm{e}}$ siècle, voir Alain GIRARD, «Le triomphe de La Cuisinière bourgeoise. Livres culinaires, cuisine et société en France aux XVII ${ }^{\mathrm{e}}$ et XVIII ${ }^{\mathrm{e}}$ siècles », RHMC, octobre-décembre 1977, p. 497-521.

51. En particulier le bœuf, viande populaire tout juste bonne pour les travailleurs de force selon les théories humorales longtemps prévalentes dans le régime alimentaire des élites, acquière peu à peu ses lettres de noblesse et gagne la table des élites sociales. J-L. FLANDRIN, « Choix alimentaire et art culinaire », op. cit. , p. 663.
} 
Galatheau : cette viande arrive en quatrième position derrière le veau, le poulet et le mouton. L'habitude nouvelle au XVIII ${ }^{\mathrm{e}}$ siècle d'indiquer avec précision les morceaux achetés révèle que notre riche Bordelaise préfère certaines parties de chaque bête: côtelettes, gigots, « rodbif ${ }^{52}$, longes, jarrets de veau, carbonades reviennent très souvent. L'inclination de Marie-Joséphine de Galatheau pour les légumes verts confirme à nouveau que Bordeaux et ses élites suivent les modes de la capitale. De manière générale, une légère augmentation de la part des légumes dans les achats est sensible entre 1754 et 1763. Elle apprécie particulièrement les artichauts, la salade et même les brocolis et les concombres. Les artichauts, très à la mode à la cour et dans les élites parisiennes ${ }^{53}$, figurent même en tête des légumes les plus courants. Enfin, la prépondérance des aromates indigènes au détriment des épices exotiques, quasiment absentes ${ }^{54}$, montre que les goûts de Mlle de Galatheau sont bien ceux de son siècle. Oignons, échalotes ou cerfeuil, pendant très longtemps considérés comme des ingrédients rustiques tout juste bon pour le peuple, sont mentionnés à plusieurs reprises. $\mathrm{Au} \mathrm{XVIII}{ }^{\mathrm{e}}$ siècle, valorisés par la littérature culinaire, ces aromates prennent une place nouvelle dans la cuisine des élites. Tous ces éléments confirment que la noblesse parlementaire bordelaise donne souvent le ton en matière de mode et que Mlle de Galatheau, dans cette capitale provinciale sensible aux nouveautés parisiennes, paraît suivre beaucoup plus les tendances de la «nouvelle » cuisine des Lumières que le marquis de Roquefeuil à Montpellier ${ }^{55}$.

À côté des achats liés à l'alimentation quotidienne, les factures de traiteurs conservées à l'intérieur du livre de comptes témoignent que, lors de repas festifs, les élites bordelaises apprécient les saveurs d'une gastronomie des Lumières où gibiers à plumes et volailles rôtis côtoient huîtres et abats. Le recours au traiteur préparant des plats ou des menus entiers servis à domicile est une habitude courante à Bordeaux où certains comme Castera ou Bardineau sont fort réputés ${ }^{56}$. Cette facture acquittée à un professionnel par Mlle de Galatheau manifeste son souci d'offrir une table de qualité aux mets raffinés en des circonstances sans doute exceptionnelles :

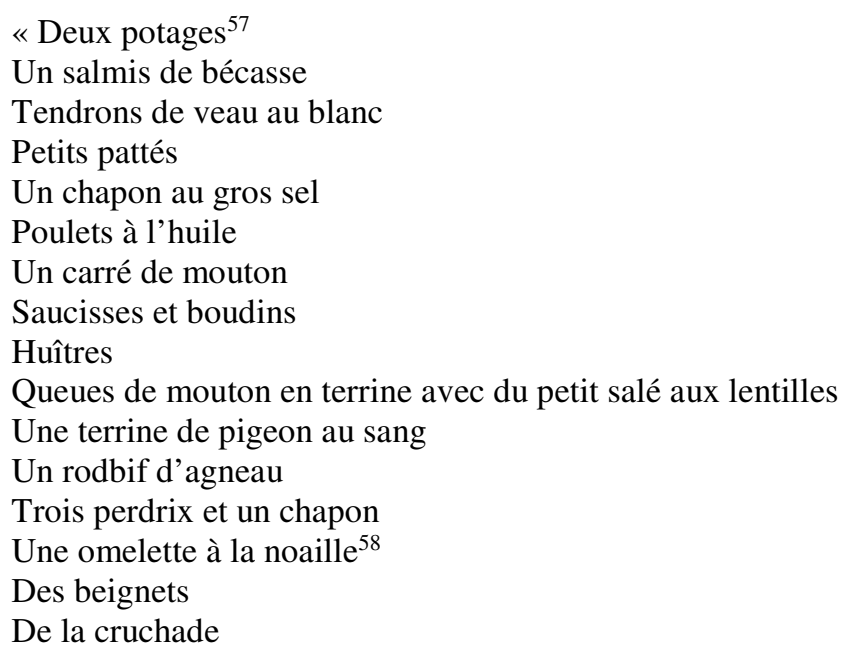

\footnotetext{
52. Cette mention confirme que la viande rouge, ici le bœuf, s'est installée définitivement à la table des élites, mais aussi que l'influence anglaise dans ce domaine a sans doute été décisive.

53. J-L. FlANDRIN, «Les fruits et légumes dans l'alimentation des élites sociales du XIV e au XVIII ${ }^{\mathrm{e}}$ siècle », dans D. MEILlER et P. VANNIER, Le grand livre des fruits et légumes, Besançon, 1991, p. 157-162.

${ }^{54}$. Nous n'avons repéré que trois achats de muscade et un seul de girofle.

55 . J. SMETS, art. cit.

56. P. MEYZIE, Culture alimentaire et société..., op. cit. , p. 292.

57. L'orthographe originale de cette facture a été conservée.

${ }^{58}$. Très à la mode dans la cuisine du XVIII ${ }^{\mathrm{e}}$ siècle, cette recette consiste à faire une omelette avec des amandes, du bœuf et du citron.
} 
Des pieds de cochon

Des cardes

Des langues fourrées »

Difficile de savoir si cette facture correspond à un unique menu complet ou si elle correspond à des plats achetés séparément par Mlle de Galatheau. Néanmoins, cette liste donne un bon aperçu de ce qui caractérise, à l'époque, la table des notables : abondance de viande et en particulier de gibiers à plumes et d'abats, légumes à la mode comme les cardes et mets élaborés comme des salmis ou des terrines ${ }^{59}$.

Quotidiennement, certains achats suggèrent des mets beaucoup plus simples et rustiques. La fourniture quasi journalière de carottes ou de raves, par exemple, laisse penser que la soupe constitue l'un des plats de base de la maison à l'usage des domestiques très certainement, mais aussi de Mlle de Galatheau elle-même car aucune précision n'indique, contrairement à ce qui peut être observé à propos d'achats de harengs ou de vin, que ces produits sont uniquement destinés aux serviteurs. De même le porc, dont l'historien limite trop souvent la consommation aux milieux populaires, fait partie de son alimentation. Régulièrement, elle achète des saucisses, des boudins, mais aussi du petit salé ou du lard, indispensable ingrédient de la soupe journalière. Souvent, à la fin de l'année, s'y ajoutent des filets, des côtelettes, des pieds et des oreilles qui proviennent sans doute de l'abattage d'un cochon domestique. La consommation de marrons, principalement durant les mois d'automne et d'hiver, fournit un indice supplémentaire sur les habitudes alimentaires de ces mangeurs pluriels aux goûts proches parfois de ceux du peuple. Cette prédilection pour les marrons, à laquelle s'ajoute celle pour les noix, qui font partie des quatre fruits les plus courants derrière les citrons et les fraises, montre qu'il n'existe pas de séparation totale entre peuple et élites, du moins au niveau des consommations journalières. Les fruits secs, habituellement assimilés à une nourriture populaire, en particulier en raison de leurs qualités de conservation, ont bien eux-aussi la faveur des plus aisés. De manière plus ponctuelle, la cruchade, qui peut être fournie par le traiteur, confirme que des plats habituellement considérés comme populaires dans les campagnes landaises, ont également droit de cité chez les notables. Cette bouillie ou galette à base de millet ou de maïs, couramment mentionnée par les voyageurs s'intéressant à la nourriture des paysans landais ${ }^{60}$, représente l'exemple assez rare mais intéressant de l'influence possible des habitudes alimentaires populaires sur les goûts des élites. La consommation de pommes, de raves ou de haricots, celle-plus ponctuelle-de pain noir ou bien encore de choux permet d'affirmer que l'alimentation des élites constitue bien une culture alimentaire plurielle où aliments de luxe et produits «populaires », distinction et rusticité cohabitent en permanence ${ }^{61}$.

L'analyse précise des dépenses de bouche de Marie-Joséphine de Galatheau révèle que les pratiques alimentaires ne peuvent se réduire à des catégories définies d'avance comme celle de consommations élitaires. Même s'il apparaît nettement que ses choix alimentaires reflètent son appartenance au milieu de la noblesse parlementaire d'une grande ville de province et son inscription dans les modes culinaires du XVIII ${ }^{\mathrm{e}}$ siècle, ils se rapprochent aussi parfois, dans l'ordinaire, des habitudes du reste de la société. Son goût pour les marrons, les

\footnotetext{
59. Le salmi est une sorte de ragoût avec des viandes cuites à la broche.

${ }^{60}$. P. MEYZIE, «Récits de voyage et tables du Sud-Ouest aquitain de la fin du XVIII ${ }^{\mathrm{e}}$ siècle au début du XIX siècle », dans Du bien manger et du bien vivre à travers les âges et les terroirs, Actes du LIV congrès d'études régionales de la FHSO, Pessac, 2002, p. 309-321

61. Le profil alimentaire de Marie-Joséphine de Galatheau correspond parfaitement aux conclusions de Michel FigEAC, Destins de la noblesse bordelaise (1770-1830), Bordeaux, Fédération historique du Sud-Ouest, 1996, T. I, p. 182: «En définitive, l'alimentation de la noblesse bordelaise à la fin de l'Ancien Régime est tout simplement celle des élites d'une grande ville provinciale. Il ne faut pas parler d'une nourriture nobiliaire, mais plutôt d'une alimentation régionale, soulignée par exemple par quelques pots à confire à tonalité urbaine. »
} 
noix, le porc ou les légumineuses en est bien la preuve. Les dépenses de Mlle de Galatheau, parfaite illustration du profil d'un mangeur pluriel, suggèrent des processus d'appropriations entre peuple et élites, des consommations qui dépassent les clivages sociaux. Ces mécanismes sont sans doute, pour une part, rendus possibles par l'existence d'une culture alimentaire régionale ou locale commune, dernière facette de l'identité alimentaire complexe de ce personnage.

\section{Des goûts bordelais}

La réalité des cuisines régionales avant la Révolution reste l'objet de nombreux débats quant à leur date d'apparition, leurs origines sociales et leurs fondements ${ }^{62}$. Différents indices, dans les dépenses de bouche de Mlle de Galatheau, permettent de penser qu'il existe bien au XVIII ${ }^{\mathrm{e}}$ siècle des spécificités alimentaires bordelaises, du moins dans les élites nobiliaires. S'il semble impossible de parler d'une cuisine locale homogène et parfaitement identifiée, on peut tout de même distinguer, grâce à ce livre de comptes, les traits d'une culture alimentaire bordelaise.

Ville portuaire installée au bord d'un fleuve, Bordeaux bénéficie de nombreuses facilités pour l'approvisionnement en poisson ${ }^{63}$. Il en résulte une très grande diversité des espèces consommées par la population et mentionnées dans le livre de dépenses de MarieJoséphine de Galatheau. Contrairement au régime languedocien du marquis de Roquefeuil ${ }^{64}$, le poisson est très souvent servi à la table de notre dame bordelaise : le poisson représente 18 $\%$ des achats auxquels s'ajoutent $2 \%$ de coquillages, mollusques et crustacés. Près d'une trentaine d'espèces différentes surgissent au détour des comptes de Marie-Joséphine.

\section{Graphique 5}

Principanx poissons achetés par Mlle de Galatheau entre 1754 et 1763

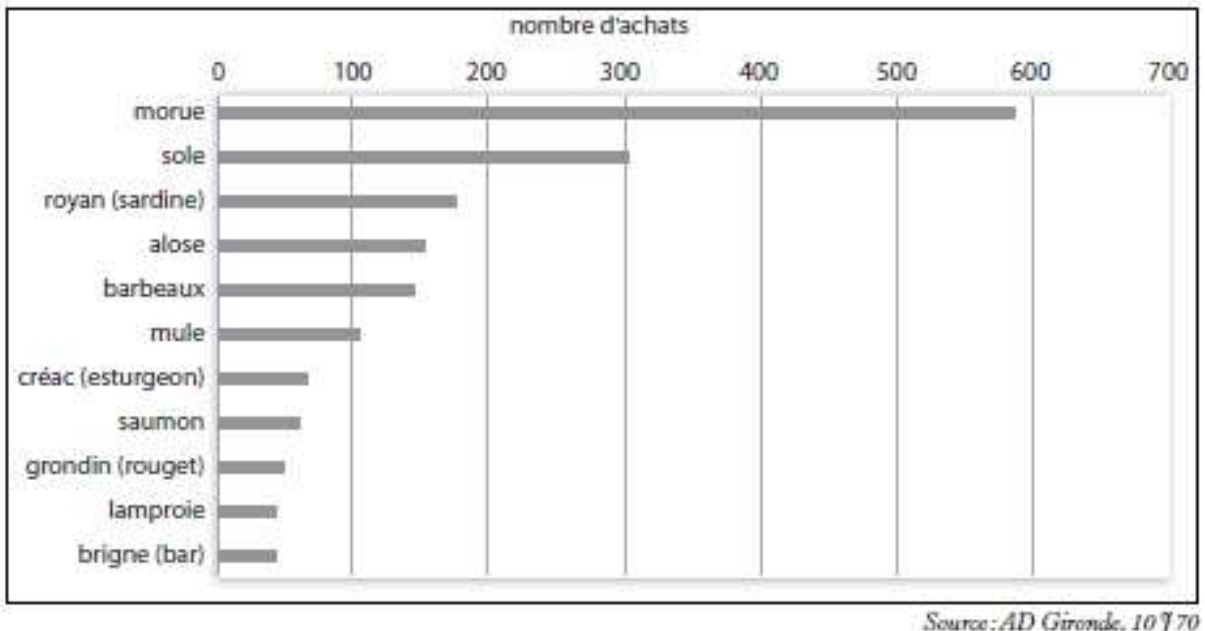

Cette variété, correspondant aux étals des marchés bordelais de l'époque, sert de base à la gastronomie locale tout au long de l'année ${ }^{65}$. Le poisson n'est pas seulement ici une

\footnotetext{
62. Julia CSERGO, «L'émergence des cuisines régionales » dans J-L. FLANDRIN et M. MONTANARI, Histoire de l'alimentation, Paris, Fayard, 1996, p. 823-841.

${ }^{63}$. La richesse et la diversité des ressources halieutiques de la région sont bien mises en évidence en 1727 par l'enquête de Lemasson du Parc, commissaire de la Marine et inspecteur général des pèches, Pêches et pécheurs du domaine aquitain au XVIII siècle. Amirautés de Bayonne et de Bordeaux, Camiac et Saint-Denis, Ed. de L'Entre-Deux-Mers, 2004.

${ }^{64}$. J. SMETS, art. cit., p. 40.

65. AM Bordeaux, HH 49, ordonnance de la Jurade portant taxe pour la vente de poisson en 1764. En ajoutant poissons, crustacés, mollusques et coquillages, on obtient un total de 80 produits différents disponibles sur le marché bordelais.
} 
consommation de Carême ou des jours maigres, mais bien un produit valorisé dans la cuisine quotidienne et festive. Mlle de Galatheau, comme l'ensemble des élites bordelaises ${ }^{66}$, apprécie en particulier la sole, mais aussi la morue, un poisson populaire dont la présence récurrente confirme toute la complexité des habitudes alimentaires des notables. La consommation de nombreux poissons migrateurs correspond à une autre tendance locale assez affirmée : lamproies, aloses, esturgeons (dénommés ici créacs), éperlans ou bien encore saumons sont très régulièrement achetés ${ }^{67}$. La Garonne et la Dordogne fournissent en abondance ce genre d'espèces dont les voyageurs soulignent souvent l'intensité de la pêche. De passage à La Réole en avril 1778, François de Paule Latapie, inspecteur des manufactures en Guyenne, remarque, par exemple, qu' « on pèche dans cette saison-ci beaucoup d'aloses dans la Garonne », puis il souligne un peu plus loin que « le saumon abonde dans la Dordogne jusqu'à Sainte-Foy $»^{68}$. Cette consommation connaît des rythmes saisonniers bien marqués. L'alose apparaît ainsi dans les comptes de Mlle de Galatheau d'avril à juin, la lamproie de fin février à début mai et les créacs de mai à août. Enfin, les dépenses de table confirment que les huîtres occupent une place de premier choix sur la table bordelaise : elles apparaissent à 93 reprises, surtout pendant les mois d'hiver et représentent $43 \%$ des coquillages, crustacés et mollusques consommés, largement devant les « chevrettes », c'est-à-dire les crevettes $(26 \%)$. D'autres poissons, a priori plus «populaires » bénéficient également des faveurs de Mlle de Galatheau. La morue, mais aussi les sardines, dénommées le plus souvent royans, sont des achats très fréquents et très ancrés dans les habitudes régionales. De même les moules, appelées parfois «charons » et consommées par tous les Bordelais, figurent aussi sur la table de cette dame (14\% des coquillages). Un goût partagé entre tous les milieux sociaux pour ces produits locaux entraîne ici la disparition de toute distinction sociale propre à l'alimentation.

Les dépenses de table de Mlle de Galatheau démontrent également que Bordeaux sait tirer profit des ressources d'un vaste arrière-pays naturel et agricole à travers les volailles, le gibier, les champignons ou les fruits. Si la volaille représente $38 \%$ des achats de viande, juste derrière la viande de boucherie (49\%), c'est surtout la grande diversité des volailles mentionnées qui révèle un goût local affirmé : poulets et poules constituent l'ordinaire de la table, mais dindes, canards, chapons et poulardes apparaissent également ici ou là. Des «pattes », «pieds » et cuisses d'oie, vraisemblablement confites, montrent que toutes les volailles, même les plus populaires, sont appréciées par Mlle de Galatheau. Cette prédilection pour des produits confits, observée chez cette riche Bordelaise, suggère que ce mode de conservation, jugé parfois rustique et qui sert à la constitution de réserves alimentaires dans les campagnes aquitaines ou à l'avitaillement des navires au départ de Bordeaux, fait partie intégrante de la culture alimentaire régionale au-delà des clivages sociaux. Parmi les gibiers, surtout présents entre octobre et février, les lapereaux et levreaux sont les plus courants chez Mlle de Galatheau comme chez $\mathrm{Mr}$ de Roquefeuil ${ }^{69}$, mais la consommation de gibier à plumes semble plus commune à Bordeaux. Sans doute le gibier est-il encore plus fréquent que ne le laissent supposer les achats, grâce à d'autres circuits d'approvisionnements comme les droits seigneuriaux, les fermages ou bien encore les cadeaux ${ }^{70}$. Le gibier, comme la charcuterie, reste avant tout des produits festifs : lapereaux, bécasses, perdrix ou saucisses sont des achats

\footnotetext{
${ }^{66}$. P. MEYZIE, « A la table des élites bordelaises au XVIII siècle », Annales du Midi, t. 115, n 241, janvier-mars 2003, p. 69-88.

67. Mlle de Galatheau achète généralement le saumon sous forme de darnes et le créac en tranches dénommées « tails », et non pas des poissons entiers, ce qui permet de penser que les dépenses de table ne concernent qu'une ou deux personnes.

68. «Journal de tournée de François de Paule Latapie, inspecteur des manufactures en 1778 », Archives historiques de la Gironde, Tome 38, p. 377 et 480.

${ }^{69}$. J. SMETS, art. cit., p. 46.

${ }^{70}$. Le gibier représente $6 \%$ des achats de viande.
} 
courants à la fin du mois de décembre. Ortolans, tourterelles et muriers ${ }^{71}$ proviennent des marais littoraux, des bords de la Garonne ou des étangs landais fréquentés par ces oiseaux migrateurs, autant de lieux où la chasse est une activité importante ${ }^{72}$. À ces pièces de gibier sont vraisemblablement associés des champignons, cèpes, mousserons, bolets, oronges ${ }^{73}$ et surtout truffes, emblèmes de la gastronomie aquitaine dès la seconde moitié du XVIII ${ }^{\mathrm{e}}$ siècle ${ }^{74}$. Mlle de Galatheau apprécie également les truffes pour farcir des dindes lors des repas de fête comme en témoigne, le 24 décembre 1757, la mention de «truffes pour la pouledinde ». Les élites provinciales, à l'image de Mlle de Galatheau, ne sont donc en aucun cas détachées de leur environnement; bien au contraire, elles y puisent, selon des rythmes saisonniers, des ressources variées qu'elles associent à des produits venus d'ailleurs et à des saveurs nouvelles ${ }^{75}$.

L'inscription des goûts alimentaires de Mlle de Galatheau dans son environnement bordelais ne se limite pas à la consommation de produits locaux à l'identité marquée, elle s'exprime également à travers des manières de faire caractéristiques de la table régionale. L'usage de matières grasses multiples constitue une pratique originale qui se retrouve dans l'ensemble de la société bordelaise. Beurre, huile, graisse et lard reviennent souvent dans le livre de dépenses ${ }^{76}$. Le beurre arrive même en tête des aliments les plus courants, position assez logique puisque cette denrée qui n'est pas produite localement doit être achetée et en petites quantités ; en dépit de telles contraintes, cette tendance révèle un véritable goût. S'il s'agit sans doute le plus souvent de beurre salé, la mention de beurre frais, en particulier sous forme de «pelote », apparaît parfois. La place de cette matière grasse découle d'un phénomène de mode dans la cuisine des élites du XVIII ${ }^{\mathrm{e}}$ siècle ${ }^{77}$, mais le beurre répond aussi à différents usages: il sert pour accompagner le poisson, pour la préparation de pâtisseries -notamment lorsqu'il est acheté en même temps que de la farine et des œufs- mais il peut être utilisé aussi comme graisse de cuisson et pour confectionner des sauces ${ }^{78}$. Cependant, pour la cuisson, l'huile, sans doute d'olive, reste vraisemblablement la plus usitée tout au long de l'année. Le cas de Mlle de Galatheau, très représentatif des mœurs alimentaires bordelaises, montre que la dichotomie trop schématique entre France du beurre, au Nord, et France de l'huile, au Sud, doit être revue; la diversité prévaut largement à Bordeaux dans ce domaine. En outre, les matières grasses n'apparaissent pas uniquement ici comme des simples auxiliaires de cuisson, elles jouent aussi également le rôle d'exhausteur de goût $^{79}$.

\footnotetext{
71. Petits gibiers à plumes proches de l'ortolan.

72. Des chasseurs professionnels, notamment dans les landes de Gascogne, se chargent de l'approvisionnement en gibier de la capitale girondine.

73. Excellent champignon comestible d'une belle couleur orange selon Tristan HoRDÉ, Dictionnaire des mots de la table. Histoire. Langue. Patrimoine, Bordeaux, Ed. Sud-Ouest, 2004, p. 285.

74. P. MEYZIE, Culture alimentaire et société...., op. cit. , p. 616.

75. Il est donc difficile de penser, comme le sociologue Jean-Pierre PoULAIN, Manger aujourd'hui. Attitudes, normes et pratiques, Toulouse, Privat, 2002, p. 31, que les élites sont obligatoirement détachées de «la niche écologique » dans laquelle elles évoluent et que la gastronomie aristocratique d'Ancien Régime se caractérise avant tout par «une faible localisation ».

${ }^{76}$. Le lard peut en effet servir de graisse de cuisson même s'il est le plus souvent consommé en tant que viande soit grillée soit, plus communément, pour agrémenter la soupe quotidienne.

77. J-L. FlANDRIN, « Choix alimentaires... », op. cit. , p. 669.

78. A travers cette utilisation du beurre, les pratiques alimentaires de Mlle de Galatheau suivent l'évolution générale de la cuisine française au XVIII ${ }^{\mathrm{e}}$ siècle, J-L. FLANDRIN, «Le goût et la nécessité : sur l'usage des graisses dans les cuisines d'Europe occidentale (XIV'-XVIII ${ }^{\mathrm{e}}$ siècles) », Annales ESC, mars-avril 1983, p. 369-401.

${ }^{79}$. Cette usage du beurre pour relever le goût des aliments se retrouve aussi dans les habitudes alimentaires populaires.
} 
L'étude des achats alimentaires de cette dame suggère aussi une cuisine relevée, s'écartant quelque peu des tendances observées à la table des élites des Lumières, qui semble correspondre à un goût local très net. Si les condiments ne représentent que $4 \%$ des achats, ces ingrédients essentiels dans la caractérisation d'une cuisine sont présents de manière très régulière tout au long de l'année. Mlle de Galatheau possède en particulier un goût marqué pour les saveurs âpres et acides alors que celui-ci semble en net recul ailleurs ${ }^{80}$.

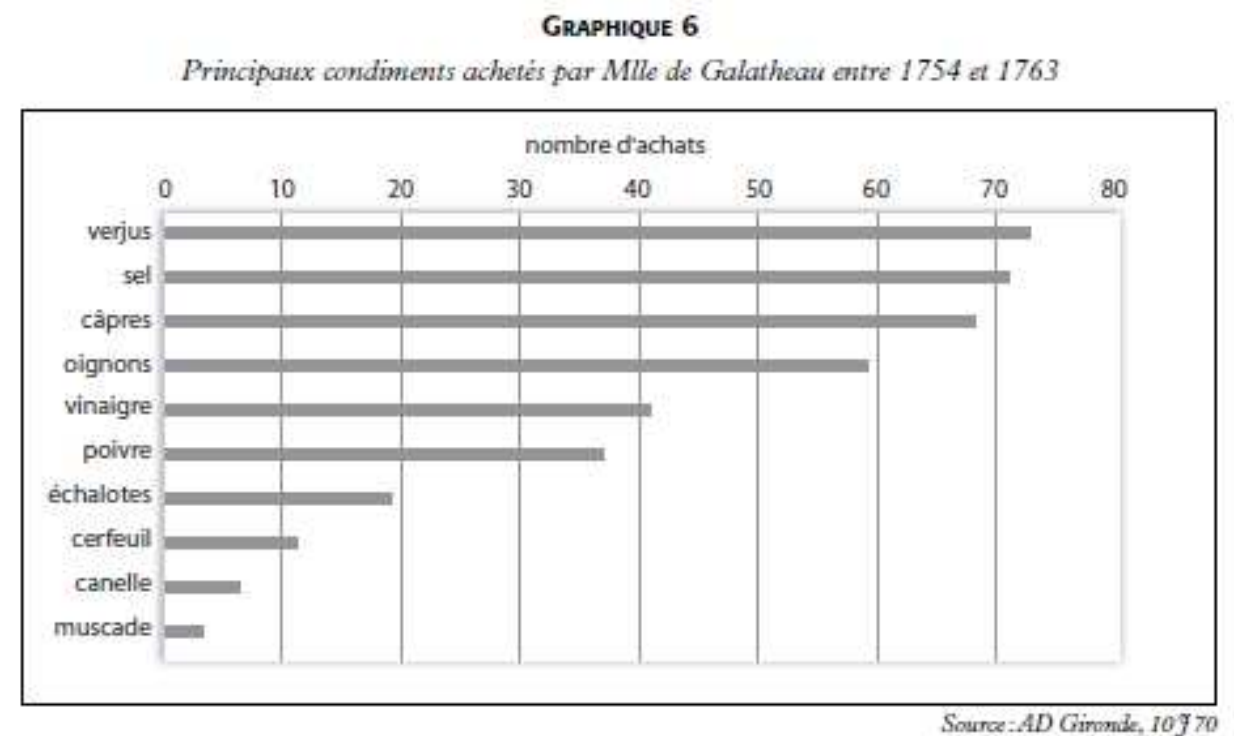

Parmi les condiments, figurent en effet en tête le verjus ${ }^{81}$ et le vinaigre auxquels s'ajoutent les citrons, souvent utilisés en cuisine, et qui occupent la première place des fruits les plus couramment achetés (168 fois). De la fréquence de ces dépenses découle une prépondérance originale de saveurs acides et, sans doute, les poulets au verjus et les sauces agrémentées de vinaigre ou de citron faisaient-ils l'ordinaire de la table de Mlle de Galatheau. Les câpres sont elles aussi très appréciées, associées surtout à la raie et au saumon, ce qui donne une touche originale à cette cuisine. À l'inverse, les épices exotiques, à l'exception du poivre, sont peu utilisées : la muscade et le girofle, d'usage courant dans la cuisine des élites du XVIII ${ }^{\mathrm{e}}$ siècle, ne reviennent que deux fois dans le registre de Mlle de Galatheau. Les plats élaborés par le cuisinier ont également pour base des fonds de veau car les comptes mentionnent à maintes reprises des achats de «fricandeaux pour le coulis» ou de «veau pour le coulis». L'utilisation de champignons pour relever le goût des plats constitue une habitude chez Mlle de Galatheau, ce qui dénote une autre tendance régionale à sa table. Truffes, bien entendu, mais surtout oronges, bolets et mousserons donnent un relief particulier aux accommodements et relient consommations populaires et élitaires, fondement de l'existence d'une culture alimentaire commune. Les indications fournies par ce document ne permettent guère d'aller plus loin dans la reconstitution des techniques et des recettes utilisées chez cette noble célibataire.

Pour saisir entièrement la complexité des goûts de cette riche Bordelaise il faut, pour terminer, s'interroger sur les aliments absents de ce livre de dépenses de table. S'agit-il de l'expression de réelles préférences alimentaires qui entraînent des exclusions ou bien de la déformation propre à une source isolée avec d'inévitables lacunes ? Certains produits, pourtant emblématiques de Bordeaux et de son arrière-pays, n'apparaissent ici malgré la

\footnotetext{
${ }^{80}$. J-L. FLANDRIN, « Choix alimentaires... », op. cit. , p. 668.

${ }^{81}$. Le verjus est un suc acide tiré des raisins pas encore mûrs et qui est employé généralement comme assaisonnement.
} 
diversité de son régime alimentaire. Assurément, le plus grand absent est le vin. En effet, à l'exception de mentions fort ponctuelles, le vin ne semble pas entrer dans les consommations quotidiennes ce qui a de quoi surprendre dans une ville totalement imprégnée par la culture du vin. Sans doute le vin n'est-il pas noté sur le registre, soit parce que Mlle de Galatheau l'achète en grande quantité deux ou trois fois par an -il fait alors l'objet de factures détaillées, soit parce qu'elle boit le vin produit sur sa propriété de Lestonnac ${ }^{82}$. Des dépenses de charrois, de bouteilles et de bouchons suggèrent que le vin de la propriété était amené en barriques et mis en bouteilles dans son hôtel bordelais. La rareté du vin n'est donc synonyme d'absence de consommation, mais plutôt du caractère tout à fait exceptionnel des achats.

De manière assez surprenante, d'autres boissons ne figurent pas, non plus, dans les comptes. Nous n'avons rencontré en effet que quelques achats épars de café, alors que Bordeaux, port colonial, importe de Saint-Domingue des cargaisons entières de café. Le 21 février 1761, Mlle de Galatheau achète 10 livres de café de Moka, illustration du goût des élites bordelaises pour ce café d'origine réputé, mais aussi peut-être de la pénurie de café des Antilles. Les difficultés d'approvisionnement engendrées par la Guerre de Sept Ans et la rupture des relations avec les Antilles entre 1756 et 1763 expliquent sans doute en grande partie cette situation sans doute exceptionnelle. Pour preuve, son frère François-Léon achète très régulièrement du café et en grandes quantités entre 1763 et 1776, période où le commerce du café à Bordeaux a retrouvé toute son importance ${ }^{83}$. Mais Mlle de Galatheau doit tout de même déguster de temps en temps une tasse de café ou, plus spécifique encore des élites bordelaises du XVIII ${ }^{\mathrm{e}}$ siècle, une tasse de thé ${ }^{84}$. Le livre de dépenses signale, en effet, à plusieurs reprises l'achat de cafetières et de théières -sans doute en argent comme les nombreuses pièces produites par les orfèvres bordelais de l'époque- mais aussi une poêle à café acquise en 1757 et un moulin à café en $1763^{85}$. Le besoin réitéré de renouveler tous ces objets liés à la consommation de ces boissons ne témoigne pas seulement d'une envie de suivre la mode en achetant telle ou telle forme nouvelle d'orfèvrerie, il révèle également le goût réel de cette dame pour ces boissons exotiques.

Finalement, seule la place extrêmement réduite du fromage pourrait correspondre à un caractère original de la culture alimentaire bordelaise. Celui-ci ne représente en effet que 1 $\%$ des achats, loin derrière les autres catégories d'aliments. Il semble que le fromage soit avant tout un aliment des jours maigres et du Carême, un produit de nécessité sans doute peu prisé en lui-même. Les produits laitiers, peu présents dans la région ${ }^{86}$, n'occupent qu'une place modeste dans le régime alimentaire de Mlle de Galatheau qui se contente de manger ponctuellement du fromage de Roquefort ou plus rarement encore de Chester et de Cluster, reflet des relations entre Bordeaux et l'Angleterre. En ce domaine, ses goûts correspondent aux habitudes du reste de la population bordelaise qui mange peu de fromage à l'exception du «croûte rouge », c'est-à-dire du fromage venant de Hollande par voie maritime. Là encore, les goûts de Mlle Galatheau témoignent de sa large imprégnation par la culture alimentaire régionale.

Le livre de dépenses de table de Mlle de Galatheau permet à l'historien de démontrer que les goûts alimentaires restent le fruit d'une alchimie complexe, parfois difficile à

\footnotetext{
${ }^{82}$. La famille Galatheau possède d'ailleurs d'autres domaines viticoles à Loupiac et exporte ces vins notamment vers le Hollande.

${ }^{83}$. AD 33 : 17 J 81 : livre de comptes de François-Léon de Galatheau, 1763-1776.

${ }^{84}$. P. MEYZIE, «A la table des élites bordelaises », op. cit. , p. 85.

85. 12 mai 1760, tasses à café ; 27 octobre 1760, une cafetière ; achat d'une théière le 19 juin 1755 , le 18 septembre 1759, le 25 février 1761 ; janvier 1757, une poêle à café ; 7 mai 1763, un moulin à café. En revanche, aucune mention n'est faite de chocolatière. Un seul achat de chocolat est noté en mars 1754 ce qui correspond bien au succès très limité de cette boisson exotique à Bordeaux, vers le milieu du XVIII ${ }^{\mathrm{e}}$ siècle.

${ }^{86}$. Pierre GuILlaume, Histoire sociale du lait, Paris, Editions Christian, 2003.
} 
déchiffrer, qui mêle la fortune, l'époque, la culture alimentaire environnante, l'habitus mais aussi la liberté de choix, reflet des préférences d'un homme ou d'une femme. Si l'appartenance sociale demeure assurément, dans cette société d'Ancien Régime marquée par un souci de distinction, l'un des traits les plus caractéristiques des habitudes alimentaires, elle s'exprime avec nuance. Les goûts de cette riche Bordelaise ne sont pas totalement séparés de ceux du reste de la population de cette ville ; soupes, marrons, bœuf, vinaigre, raves ou morue servie à sa table montrent que l'opposition binaire entre consommation populaire et consommation des élites ne correspond pas tout à fait à une culture alimentaire plurielle qui fait fi de toute classification hermétique. Bien entendu par son goût pour les ortolans, les chapons, les huîtres, le veau, les soles et les artichauts, Mlle de Galatheau reste la parfaite représentante d'une noblesse bordelaise à la pointe de la gastronomie locale, mais elle exprime également, par des consommations plus rustiques, son immersion dans des habitudes alimentaires bordelaises partagées par tous comme l'usage de plusieurs matières grasses, le goût de saveurs relevées ou bien encore la consommation de poisson de mer frais et de gibiers à plumes. L'analyse d'un document isolé, comme le livre de dépenses de table de MarieJoséphine de Galatheau, ne permet pas à lui seul de reconstituer la culture alimentaire bordelaise du siècle des Lumières. Seule une approche comparative avec des sources émanant d'autres groupes sociaux et surtout d'autres régions pourrait permettre de déceler les contours d'une véritable originalité qui devrait aussi prendre en compte la spécificité des manières de faire, c'est-à-dire les façons de cuisiner qui restent bien souvent inaccessibles à l'historien ${ }^{87}$. L'exemple de Marie-Joséphine de Galatheau suggère cependant qu'il existe bien des nuances locales dans l'alimentation et que l'identité régionale peut résulter des pratiques socialement différenciées. Les élites provinciales, que ce soit ici la noblesse, mais aussi les négociants ou les magistrats municipaux ${ }^{88}$, par la complexité de leurs goûts, contribuent, à la fin du XVIII ${ }^{\mathrm{e}}$ siècle, à l'émergence d'une véritable gastronomie régionale.

\footnotetext{
${ }^{87}$. La mise en série des livres de compte ou des livres de raison est une voie possible pour gommer les effets déformants de ce type de sources analysées de manière isolée, Michel CASSAN, «Les livres de raison, invention historiographique, usages historiques », dans J-P. BARDET et F-J. RUGGIU, op. cit. , p. 15-28.

${ }^{88}$. M. FIGEAC, «Les pratiques alimentaires de la noblesse provinciale à la fin du règne de Louis XIV : l'exemple de la Guyenne », XVII siècle, oct-déc. 2002, p. 643-654; P. MEYZIE, « La table de la Jurade, haut-lieu de la gastronomie bordelaise au XVIII ${ }^{\mathrm{e}}$ siècle », dans Annie HUBERT et Michel FIGEAC (dir.), La table et les ports. Cuisine et société à Bordeaux et dans les villes portuaires, Pessac, PU de Bordeaux, 2006, p. 63-83.
} 